\title{
Testate Amoebae Diversity, from the Atlantic Forest Aquatic and Edaphic Environments, Collected Within the Rio de Janeiro State, Brazil.
}

Inácio D. da Silva-Neto ${ }^{1}$, Anderson G. S. Silva ${ }^{1}$, Pedro H. C. Nunes ${ }^{1}$, Gisele R. Santos ${ }^{1}$, Marcelo H. de O. Sales ${ }^{1}$, Thiago da S. Paiva ${ }^{1}$, Luiggia G. B. R. Araujo ${ }^{1}$ and Breno Leite ${ }^{2}$

1. Dep. de Zoologia, Inst. de Biologia, Universidade Federal do Rio de Janeiro, Brasil

2. JEOL USA, Inc., Peabody, MA, USA

(idsnet@biologia.ufrj.br)

Atlantic Forest is considered one of world's most species-diverse ecosystems, with high endemism rate and often referred as a diversity hot-spot. [1,2]. Due to anthropic activity since the 1500's, it has been constantly reduced until only ca. $7.9 \%$ of its original area remains intact [2]. In the state of Rio de Janeiro, the Atlantic Forest originally covered $98 \%$ of its territory, while currently its extension is less than $17 \%$. Considering such scenario and the eventual possible implications of huge diversity losses, it is important to study species diversity within an alpha-taxonomy (i.e. descriptive taxonomy) context. The present study is part of a Brazilian program called BIOTA-FAPERJ (E26/110.022/2011), which aims to investigate the diversity of microeukaryotic organisms present in various environments of the Atlantic Forest in Rio de Janeiro, using morphological and molecular approaches. The program also has the objective to investigate the biotechnological potential of these organisms in improving environment quality.

Testate amoebae are free-living, heterotrophic, microeukaryotic organisms which are polyphyletic, representing various lineages among the eukaryote tree, most associated to the Arcellinida (Amoebozoa), but slightly related to Labyrinthulomycetes (Stramenopiles) Rhizaspididae (Rhizaria) [3]. Such microeukaryotes have their bodies protected by a shell, of which morphology is largely used for species identification. While carrying out this study, testate amoebae were isolated from: a) sediments from water samples collected from streams, ponds, and bromeliad tanks; and b) from soils obtained from various locations in the Rio de Janeiro Atlantic Forest. Samples were split into Petri dishes and raw mass cultures were kept in the laboratory. The organisms were morphologically identified under stereomicroscope. The testate amoebae were photographed under differential interference contrast (DIC) and then observed a under scanning electron microscopy (SEM). We documented more than 80 species (Figure 1), mostly assigned to Arcellinida and Euglyphida, many are new occurrences, of which the most frequent were Arcella hemisphaerica hemisphaerica, A. hemisphaerica undulata, A. braziliensis, A. vulgaris, Centropyxis aculeata, C. aculeata oblonga, C. spinosa, C. platystoma, Difflugia corona, D. acuminata, D. cylindrus, D. elegans, D. achlora, D. penardi, Ciphoderia ampulla, Euglypha filifera, E. ciliata, Trinema lineare, Lesquereusia globulosa, L. modesta minima e Protocucurbitella coroniformis var. ecornis. The comparison with other geographic regions of the world, by tabulating the number of testate amoebae species, indicated high diversity within these areas. This study is the one of the first steps to fill the current gap in the knowledge of microeukaryotic diversity in Brazil.

\section{References:}

[1] Myers N (1988) The Environmentalist 8: 1-20.

[2] Myers N (1990) The Environmentalist 10: 243-256.

[3] Adl SM et al., (2012) Journal of Eukaryotic Microbiology 59: 429-493.

Authors acknowledge Dr. Maria Ishida (FDACS) and Dr. Natasha Erdman (JEOL USA Inc) for critically reviewing the manuscript. 


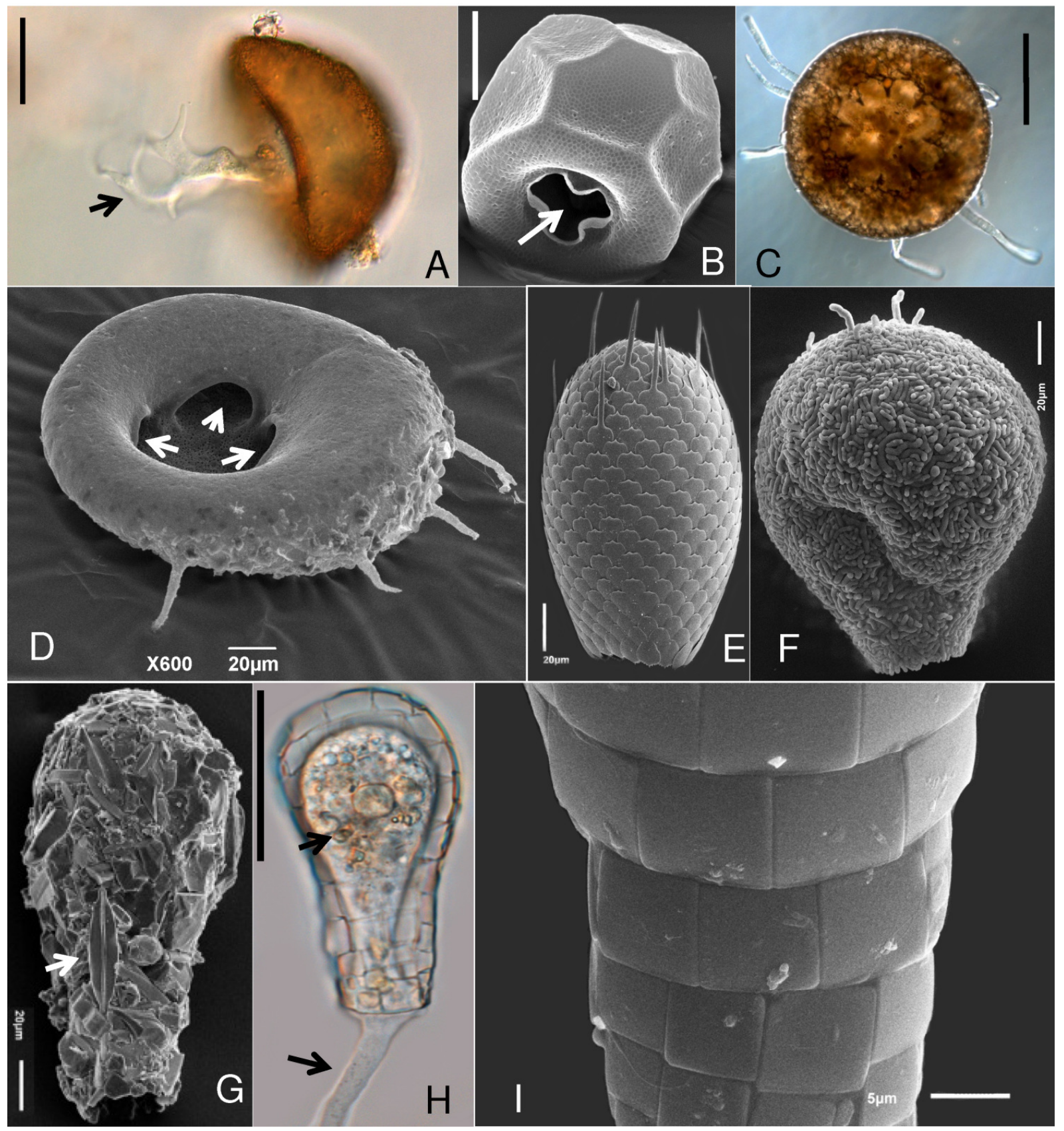

Figure 1. Arcella vulgaris stretching its pseudopodia (from life), scale bar $=25 \mu \mathrm{m}$ (A); Arcella gibbosa with a three-lobed pseudostome (arrow), scale $=25 \mu \mathrm{m}(\mathrm{B})$; Cyclopyxis impressa with pseudopodia and pseudostome shown in the same image (from life), scale $=100 \mu \mathrm{m}$ (C); Centropyxis spinosa with various shell apertures (arrows) (D); Euglypha sp. with regular, but complex scales (E); Lesquereusia extranea, with a very peculiar pattern of "scales" (F); Difflugia bacillifera showing pieces taken from the environment build its shell, a diatom frustule is shown (arrow) (G); Quadrulella symmetrica var. tubulata with protruding pseudopod (large arrow). Soft body can be seen inside shell (small arrow) amoeba can be seen inside (from life), scale bar $=25 \mu \mathrm{m}(\mathrm{H})$; Quadrulella symmetrica var. tubulata exhibiting the pattern of shell plates (I). 